\title{
MEMORY DISTURBANCES IN THIRD VENTRICLE TUMOURS
}

\author{
BY \\ MOYRA WILLIAMS and JOE PENNYBACKER \\ From the Nuffield Department of Surgery, Oxford
}

As has been stated by Busch (1940), the study of localized disease of the brain has always had especial interest because it raises the possibility that analysis of the concomitant psychological disorders may clarify some of the connexions between mind and brain.

A mental function of basic interest and importance is that of memorizing, and considerable efforts have been made to define the lesions involved in impairment of this function. Although it is now widely recognized that some degree of memory is involved in all forms of intellectual behaviour, and, at the same time, some degree of memory impairment always accompanies intellectual deterioration, cases are not infrequently observed in which the ability to retain and recall recent events seems to be impaired out of all proportion to other mental defects. Such cases, first described by Korsakov (1889), can occur in a variety of different clinical conditions, but there is a considerable volume of literature suggesting that the accompanying lesions tend to centre around the floor and sides of the third ventricle. Thus, in the necropsy studies of patients who during their lives had shown Korsakák's psychosis from chronic alcoholism Gamper (1928) found that the majority of lesions were concentrated around this area, while conversely Campbeli, and Russell (1941) noted that in the cllnical history of patients with Wernicke's lesions acute confusional and amnesic states were extremely frequent. Again, Busch (1940) concluded from his analysis of the mental disturbances seen in 662 unselected tumour cases that impaired memory, while not closely associated with raised intracranial pressure, -was most frequent in the intracerebral lesions surrounding the third ventricle.

Papers have also appeared from time to time reporting individual cases of amnesic states due to localized lesions which were verified by operation or at necropsy. In these instances. the lesion has always been a deep mid-line one, involving the grey matter around the third ventricle (Foerster and Gagel, 1934 ; Lhermitte, Doussinet, and Ajuria- guerra, 1937 ; Hermann, 1950 ; Benedek and Juba, 1941 ; Conrad and Ule, 1951; Sprofkin and Sciarra, 1952). In the case reported by Foerster and Gagel, that of a cranio-pharyngeal cyst, the mental symptoms cleared up as soon as the cyst was emptied and the cyst wall surgically removed.

As against these reports, however, there are also a great many other observations indicating that the impairment of memory is a frequent and nonspecific sequel to diffuse and widespread brain damage. Carmichael and Stern (1931) examined the brains of five patients said to have exhibited Korsakov's syndrome and noted that the histological changes were chiefly seen in the cortex of the prefrontal areas. In only one case were there additional lesions in the thalamus. Walther-Büel (1951) studied the psychiatric disturbances in 600 unselected tumour cases and found that the "organic psycho-syndrome", consisting largely of memory impairment, occurred in the vast majority of all those over 40 years old. McFie and Piercy (1952), from a systematic psychological study of patients with localized brain lesions, also concluded that general failure of retention, irrespective of the material to be retained or locus of the lesion, was the most common defect. Finally, specific studies of the mental symptoms associated with colloid cysts of the third ventricle indicate that, although memory disorders may be severe and outstanding symptoms in a few cases, they are more usually completely absent except as transitory signs immediately after operation (Cairns and Mosberg, 1951 ; Poppen, Reyes, and Horrax, 1953). These tumours, however, grow from the anterior-superior part of the third ventricle and may occlude the foramina of Monr. The side walls of the ventricle may be subjected to pressure, but the floor usually escapes.

It is the aim of this paper to report further observations which we consider may indicate that specific disorders of memory may arise from focal lesions in the region of the third ventricle. Between June, 1950, and June, 1952, 180 patients in whom intracranial lesions were verified at operation, 
necropsy, or by encephalography in the Nuffield Department of Surgery, were subjected to psychological investigations designed to elicit signs of gross memory defects where these existed. Whenever possible mental tests adapted from the Wechsler, Babcock, or Binet scales were also given, but these usually had to be modified to the individual circumstances.

The data obtained from this investigation have been analysed from three aspects : (1) Special attention has been given to those patients in whom both memory disturbances and site of lesion were well defined and carefully studied. (2) The incidence of memory disorders in lesions involving different cerebral areas has been estimated and compared. (3) Those patients who showed profound and specific memory disorders have been separated from the others and compared as regards the site of the lesion.

\section{Cases of Well Defined Memory Disturbance and Site of Lesion}

Only four of the 180 patients interviewed could be included in this group, and they will be described in detail.

Case 1.-F. T., a mechanical engineer aged 50 (R.I. No. 125648/50), was admitted to the Radcliffe Infirmary on June 3,1950, complaining of deterioration of vision for two years, excessive sleepiness for 22 months, loss of libido, right frontal headache, and failing memory for two months. It appears that two years previously he had gone to see a specialist in Canada who found evidence of chiasmal compression. This was explored, but no abnormalities were detected. His eyesight failed to improve, but his general health remained fairly good until the onset of headache and sleepiness which prompted him to seek further advice.

On admission he was found to be a healthy, robustlooking man, cooperative but drowsy. He would spend most of his time sleeping, but roused easily and then appeared to be rather disinhibited. The neurological examination revealed slight bilateral primary optic atrophy, with a bitemporal field defect and reduction of visual acuity to finger counting in the right eye and J.14 in the nasal field of the left eye. There were no other abnormalities. Radiographs of the skull were normal, but an air encephalogram showed a large ovoid tumour virtually filling the third ventricle. An electroencephalogram showed that general slowing of the alpha rhythm to $7-8 / \mathrm{sec}$. was the most prominent feature, but this was inhibited on opening the eye. He showed some $4 / \mathrm{sec}$. groups frontally on over-breathing and also a small amount of 14-16/sec. activity-possibly connected with his drowsiness.

Mentally, he was fully orientated in time and space and had some insight into his disturbances. He was able to give a coherent account of his past and of the events leading up to his admission. On memory tests it was found that, although immediate memory span was normal as judged by sentence repetition, learning ability was severely impaired. Delayed recall was also defective. After the lapse of 12 hours he had little recollection of the tests he had been given. If the original material was presented to him again, he might claim it as familiar, but overestimated the time since its previous presentation. He also tended to confabulate. Intellect and judgment appeared well preserved.

On June 19, 1950, a craniopharyngioma in the third ventricle was removed by a right transventricular approach. He came round from the operation an hour or two after returning to the ward and was very brighta little disorientated, but talking sensibly. The following day he was noted to be outstandingly euphoric. He was also inclined to be restless and to get out of bed, and he began confabulating in earnest. He retained correct orientation in time and space, but mistook hospital personnel for his relatives, told stories of long telephone calls he believed he had made since his operation, and described a number of other fictitious experiences. He was still able to describe correctly events leading up to his admission to hospital, but was unable to recall test material presented to him either before or since operation.

Over the succeeding few days he continued to show the same mental condition with little insight into his disturbances. He believed he was improving daily and that his memory was almost perfect.

On June 25, 1950, he appeared to regain some insight into his delusions and was able to accept a suggestion that the peculiar events he described might be imaginary. None the less, he continued to confabulate new stories. Perception and judgment were also much impaired. Although able to name the pictures on the Wechsler Picture Completion Test, he failed to appreciate any of their missing pieces and was unable to recall any of the pictures a few minutes later.

On June 29, 1950, eight days after operation, he began to get up and about the ward. He appeared at first to have little recollection of its geography from his pre-operative experience, but soon learned his way around. As he did so, many recollections of pre-operative events which had been forgotten or denied came back to him.

Over the next few days there was a steady improvement in insight, memorizing, and judgment. New confabulations were absent, and on the Wechsler Similarities Test he produced a score equivalent to an I.Q. of 135 . However, although he was able to remember the majority of tests from one day to the next, he still showed some uncertainty of memory.

He was discharged on July 5, 1950. Apart from his visual acuity, the field defects, and the loss of libido, none of which had improved, he had no cranial nerve deficiencies, and the motor and sensory functions were normal. The headaches and drowsiness of which he had complained on admission no longer worried him, and his memorizing had so improved that he showed no defects on formal testing.

Unfortunately, the patient returned to Canada soon 
after his discharge, so that opportunities for follow-up studies were not available.

Case 2.-E.S., a schoolmistress aged 51 (R.I. No. 147029), was admitted to the Radcliffe Infirmary on October 24, 1951, after transfer from a mental hospital where she had been for about six weeks as a voluntary patient. The history was supplied by her family and by a sister from a neighbouring convent where she had been staying at the onset of her illness. According to her family, the patient had always shown some peculiarities of personality, but she was able to look after herself, earn her own living, and had travelled widely. She was in the habit of spending some months each summer in retreat in the convent where she was taken ill. Nothing abnormal had been noted about her until about three months before her admission to hospital, when she had had several lapses of memory and it was decided that she should resign her teaching job.

During the week before her admission to hospital she became confused and disorientated. On September 3 , 1951, she complained of a headache and was told to lie down. On September 6 she vomited and became drowsy, and the belief that she had been taking drugs led to her admission to hospital.

During the week following her admission to the mental hospital the patient vomited once or twice a day. Her pulse remained at about 60 , but there were no neurological signs. She was transferred to the Churchill Hospital for further investigation, and two air encephalograms were performed, both with equivocal results. On physical examination she was an obese middle-aged woman, and her mental state was such that it was difficult to carry out a full neurological examination. There was no anosmia, the optic discs were pale (but she was highly myopic), and no definite field defect could be demonstrated on confrontation. There was possibly a slight relative weakness of the right limbs, but it was very slight, and there was no alteration in the reflexes, nor any sensory defect. The blood pressure was normal $(150-90 \mathrm{~mm}$. $\mathrm{Hg})$ and the general systemic examination was normal. Radiographs of the skull showed no abnormality, but a ventriculogram revealed a considerable hydrocephalus due to a tumour in the third ventricle. The electroencephalogram showed episodes of high-voltage $2 / \mathrm{sec}$. waves, maximal frontally, of the type seen with lesions of the upper brain-stem. In between episodes the alpha was fairly well preserved and mixed with a $16 / \mathrm{sec}$. beta component.

Mentally, the patient was drowsy, but wakened easily and would remain awake so long as her attention was being occupied. She was disorientated for time and place, apparently believing herself to be near her home, but realizing at the same time that her immediate surroundings were unfamiliar. Her manner was blusteringly jovial, and her social responses were fairly well preserved. On tests of reasoning and abstraction she still showed considerable ability, but on tests of free association she showed concreteness, her responses consisting chiefly of rhyming or completion words (e.g., red-fed ; grass-brass ; pale-pink).
Memory tests revealed a high degree of amnesia for recent and remote events. To direct questioning she was able to give a few outstanding facts, without details, about the last world war and about her personal past, but they were very much confused. Immediate memory span, as measured by repetition of digits, was about average, but learning and delayed recall were extremely poor. Test material, if recognized, was displaced in time and referred to the wrong contexts. There was little apparent disturbance of speech, but there was some dyslexia and dysgraphia; she was fully continent.

At operation on October 25, 1951, a craniopharyngioma in the third ventricle was partially removed.

On returning to the ward the patient's general condition was good. An hour later she was able to answer questions. The following morning she appeared to be in much the same mental condition as before operation, except for her speech. Although this was fairly fluent and well formed, she seemed to have some difficulty in finding words, and her sentences were confused. She was grossly disorientated in time and space. She appeared to believe that she was still working in a school, and she confabulated freely.

The following day she was less well. She answered questions more slowly and only after long pauses. There was much oedema of the face and around the wound. Lumbar puncture showed blood-stained fluid at a pressure of 450 . Her temperature was $101^{\circ} \mathrm{F}$. Reduction of lumbar puncture pressure caused a slight improvement in responsiveness, but she was no less confused. She became progressively less responsive and died three days later.

At necropsy, examination of the base of the brain revealed a yellowish cystic tumour, apparently arising from the upper part of the stalk of the pituitary gland, and largely filling the floor of the third ventricle. On sagittal section the tumour was seen to occupy the floor of the third ventricle, projecting forward above the

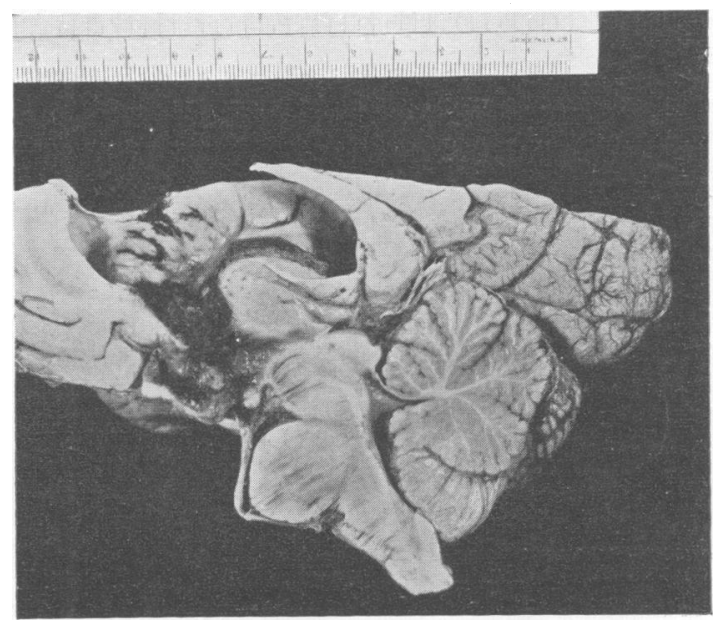

FIG. 1.-Median sagittal section of brain showing tumour (craniopharyngioma) in the floor of the third ventricle. 
optic chiasm (Fig. 1). It measured $2 \mathrm{~cm}$. from before back $\times 1 \mathrm{~cm}$. from above down $\times 2 \mathrm{~cm}$. from side to side. The dark area above this is the operative cavity in the anterior part of the third ventricle. Both pillars of the fornix were divided at operation. There was a moderate internal hydrocephalus.

Histologically the tumour had all the features of a craniopharyngioma.

Case 3.-D. W., a woodwork machinist aged 63 (R.I. No. 157481), was admitted to the Radcliffe Infirmary on May 1, 1952, complaining of headache, falling attacks during which consciousness was occasionally lost, progressive failure of memory for about 18 months, together with some failing vision more recently. There was also a history of recent excessive thirst.

On physical examination he was a tall, obese man, with a smooth skin and scanty pubic and axillary hair. Genital development was normal. There was bilateral papilloedema, a bitemporal field defect, and reduction of visual acuity to $6 / 9 \mathrm{~J} .16$ on the right, $2 / 60$ and finger counting on the left. There were no other neurological defects. Radiographs of the skull revealed some enlargement and erosion of the sella turcica with a good deal of calcification above it.

An electroencephalogram showed a poorly represented alpha rhythm, a dominant frequency of $6 / \mathrm{sec}$., and diffuse slow activity. Episodes of high-voltage 1-2/sec. waves were prominent in the left temporal leads.

Mentally, he was drowsy, but always roused easily and cooperated willingly. He was, however, extremely distractable and easily fatigued, so that the examination had to be carried out in a series of short sessions, during each of which he gave the impression of being slightly disinhibited and emotionally labile.

He was fully orientated in time and space and could give a detailed account of his past, including the events leading up to his admission; but his performance on simple tests of general knowledge suggested that there was some impairment of memory for well established learning.

Intellect appeared to be a low average, and his immediate memory span, as measured by retention of digits, was small. There was also some impairment of learning and of delayed recall.

On May 8, 1952, a ventriculogram was performed. Pressure was $170 \mathrm{~mm}$. and the ventricle communicated freely, probably through a patent septum pellucidum. The radiographs showed considerable symmetrical hydrocephalus due to occlusion of the third ventricle by a large spherical tumour. The ventriculogram was followed by cerebellar decompression and ventriculocisternostomy. The operation was well tolerated, and the following morning he appeared alert and comfortable.

During the first post-operative week the patient was very drowsy and became truculent when roused. It was difficult to gain his cooperation on formal tests, although the responses that he did give indicated slight further deterioration of intellect and further gross memory impairment. Orientation fluctuated, apparently with his degree of wakefulness. He had difficulty in keeping track of the time, and on several occasions maintained that the ward in which he was now being nursed was a different one, although similar, from that in which he had been before. He was never, however, in any doubt about being in Oxford.

His performance on the same tests as those conducted before operation showed that memory span was little affected, but learning and delayed recall were markedly impaired.

He was restless, being inclined to get out of bed two or three times a day for no reason, and incontinent.

Physical examination during this first post-operative week showed improvement of vision, especially in the left eye, and a subsidence of the papilloedema. At lumbar puncture it was found that during the first few days after the operation the fluid was bloodstained and at a pressure of $240-300 \mathrm{~mm}$. Hg. This improved, but by May 25, 1952, the skin at the site of the wound became red. A low-grade inflammation of the posterior fossa was suspected, and he was put on a course of sulphadiazine with good results.

During the following week there seemed to be a slight deterioration of alertness. His responses to verbal intelligence tests were of a poorer quality even than before, and he was also unable to say how he had come into hospital and what he had been doing before his illness. He maintained that he had left the Radcliffe Infirmary and was now living near his niece in Scotland. He usually recognized hospital personnel, however, although he was not able to remember their names.

On June 3, 1952, about $10 \mathrm{ml}$. of yellow fluid was withdrawn from the cystic part of the tumour by needle through a right frontal burr-hole. After this he appeared to become a little more alert, but there was little improvement in his confusion, disorientation, or memory. His speech was brisker, but still rambling, and he was now unable to say (without looking) what he had on his bedside locker.

By June 10 he was noted to be much more awake and showed signs of confabulating for the first time. He was sitting up in a chair for part of each day.

During the next few days the tendency to confabulate increased, together with alertness, responsiveness, and apparent improvement in intellectual control. But the memory defects remained as gross as before and therefore became more obvious. When taken by an attendant for walks about the corridors he would be quite unable to find his own way back to the ward; he denied that he had ever slept in the hospital, failed to recognize hospital personnel (or misidentified them with former acquaintances), and refused to own any of the possessions in his bedside locker.

On July 1, 1952, still presenting the above picture, he was transferred to another hospital (Royal Berks) for further observation.

Case 4.-G. P., a farm labourer aged 22 (R.I. No. 111669/49), was admitted to the Radcliffe Infirmary on September 10,1949, complaining of drowsiness during the past six months and vomiting and frontal headaches for four days. He had been unable to work for the 
preceding three months, and three days before admission had been sent home from the lodgings where he lived as he could not keep awake. His relatives reported that he had been excessively thirsty for the last year or so and had admitted to lack of libido.

On admission, he was a small man, with a smooth chin and hairless skin, and pronounced genital hypoplasia. He was very drowsy, but could be roused to cooperate in a modified examination. There was no papilloedema, nor did there appear to be any hemianopia. The pupils and ocular movements were normal, and the only definite neurological defect was a slight left hemiparesis with a corresponding alteration in the reflexes. The blood pressure was $90 / 70 \mathrm{~mm}$. $\mathrm{Hg}$. Radiographs of the skull showed a good deal of calcification in and above the sella turcica, the appearances being characteristic of a craniopharyngioma.

Mental examination revealed that he was very drowsy but rousable by speech and by painful stimuli. His memory was not tested. Later that evening he went into coma. At operation a left frontal burr-hole was made and the ventricular pressure was found to be over 600. After this was relieved the patient once more responded to speech.

Three days later he became drowsy and unresponsive again, and was lying in a typical decerebrate posture. Ventricular tapping did not alter his condition, but after the removal of $33 \mathrm{ml}$. of fluid from a suprasellar cyst the patient recovered to the extent of responding to speech again. By the following morning he was alert and orientated. He could give his personal history and remember what he had had for breakfast. The electroencephalogram, which before operation had shown a preponderance of slow waves, came back to normal more slowly.

The patient remained well for a few days, but on September 18 he began to get drowsy again. Ventriculocisternostomy was performed on September 19, but although it appeared to deal adequately with the pressure situation the patient's mental state remained unaltered.

On October 1 the cyst was tapped again, with the removal of about $10 \mathrm{ml}$. of fluid. After this the patient's mental condition improved somewhat. He became alert, and slightly aggressive, and was noted to present features typical of Korsakov's psychosis. He was disorientated for time and place and could not find his way back to his bed after leaving the ward. He was unable to recall day-to-day events, such as what he had had for meals, the visits of doctors, etc., and he was easily led to confabulate about his recent past. He slept a good deal, but roused easily. Occasionally he was incontinent.

These defects gradually cleared up, and on October 17 he appeared to be more or less rational. Three days later, however, he began to get drowsy and confused again, vomiting and confabulating, and showing gross amnesia. On October 23 he collapsed at lunch and was in stupor for some minutes. Later that day ventricular pressure was found to be within normal limits, but the cystic part of the tumour had reaccumulated. After aspiration of $30 \mathrm{ml}$. of fluid from the cyst the patient's mental condition began to improve. He remained confused and disorientated for the rest of that day, but on the following day there was considerable improvement. When he started confabulating he would pull himself up, look puzzled, and say he knew that something was wrong.

The electroencephalogram, which before aspiration of the cyst had shown large 100 microvolt $1-2 / \mathrm{sec}$. waves typical of coma, showed a rapid return of alpha rhythm ; a good 8-10/sec. appeared at a record taken 10 minutes after aspiration. This continued to improve over 24 hours. The records in this case have already been referred to and illustrated elsewhere (Cairns, 1952).

The patient thereafter had a long and fluctuating illness, during which the above sequence of events was repeated on numerous occasions. On each occasion that the cyst began to reaccumulate the first sign of deterioration was the presence of slow waves in the E.E.G., after which the patient showed signs of becoming drowsy and amnesic. Although usually able to recount his personal history and to repeat an average number of digits forwards and backwards, he would be unable to find his way back to his ward if he left it, but would recognize his bed when he saw it again. He would start to recite poems which he said he knew, but seldom get beyond the first line. After this he would wander from the point and improvise.

Each time that the cyst was successfully aspirated his mental condition improved in parallel with recovery of alpha rhythm in the E.E.G. On two occasions (December 28,1949 , and January 24,1950 ) the patient appeared to be so well that he was allowed to go home. The improvement was only short-lived, however, before his mental condition deteriorated and he had to be readmitted. On each occasion ventricular tapping had little effect, but aspiration of the cyst was followed by striking improvement of both E.E.G. and mentality.

After his third admission in January, 1950, he was seen to show some deterioration of personality as well as chronic impairment of memory in the periods of remission. When seen by a psychologist (Miss M. Davidson) on April 16, 1950, he was found to have a vocabulary level up to that of an average adult, but severe impairment on a wide range of memory tests involving orientation and the ability to keep the goal in view.

As the patient appeared to be losing ground, it was decided to try a more radical operation. An attempt was made on June 1, 1950, to drain the cyst into the ventricle, but the patient never fully recovered from the operation and died three days later.

At necropsy there was a nodular cystic tumour covering the base of the third ventricle. It measured $4.5 \mathrm{~mm}$. from before back $\times 2.5 \mathrm{~cm}$. from side to side $\times 2.5 \mathrm{~cm}$. from above down. Anteriorly it was in contact with the optic chiasm, and the cerebral peduncles were stretched over its lateral margins. In a mid-sagittal section of the brain tumour could be seen to occupy the floor of the third ventricle and the interpeduncular space (Fig. 2). This part of the tumour was solid : the collapsed cyst could be identified on its upper surface in the lower part of the third ventricle. Coronal sections showed that the tumour invaded the antero-inferior part of the left 


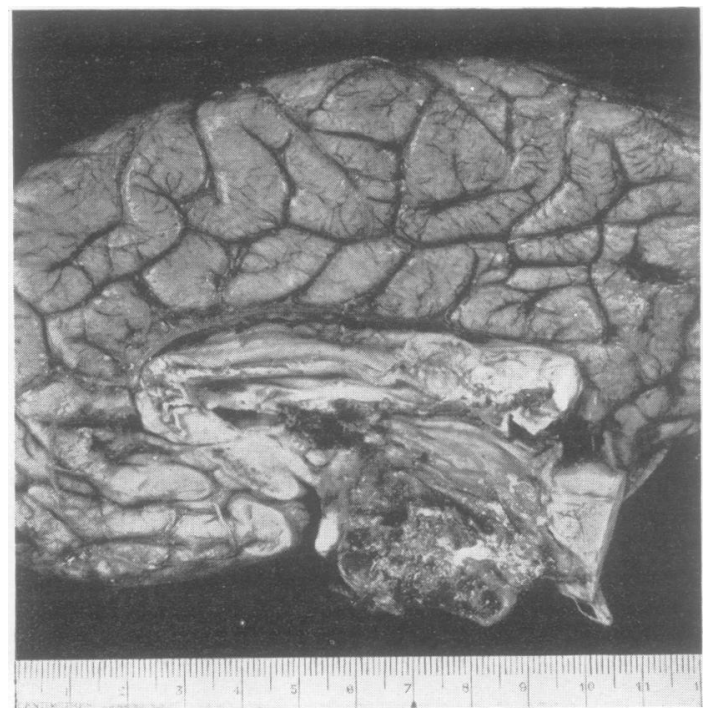

Fig. 2.-Median sagittal section of brain showing tumour (craniopharyngioma) in the floor of the third ventricle and interpeduncular fossa.

thalamus. There was a moderate internal hydrocephalus.

Microscopic examination of the tumour showed it to be a craniopharyngioma.

Mental Aspects.-Each of the four cases described here exhibited the mental picture of Korsakov's syndrome, consisting of some impoverishment of intellect, changes of personality (usually euphoria or apathy), disorientation, confabulation, and impairment of memory. Since it is the last which is the chief concern at the moment, the other defects may be temporarily disregarded.

The memory defects consisted of $(a)$ inability to retain new impressions for any length of time; (b) inaccessibility of memory for past experiences ; (c) distortion and fractionation of recent memory ; (d) inability to learn new sensorimotor habits. Immediate memory span, as measured by repetition of digits or sentences, was comparatively well maintained in all patients.

Site and Extent of Lesion. - In each of these cases there was a well defined lesion involving the floor and sides of the third ventricle. In Cases 1 and 2 there was no evidence of pressure on other areas of the brain, and in Cases 3 and 4, where intracranial pressure was originally high, this was relieved without affecting the amnesia.

\section{Incidence of Memory Disorders in Third Ventricle Tumours}

Although in the four cases quoted above the mental disturbances and site of lesion were strikingly uniform, doubts may be felt regarding the frequency of such instances. How often are similar mental pictures seen in association with such lesions, and how often are such mental pictures seen in lesions involving other areas of the brain? In order to answer the first of these questions it was decided to examine the notes of all patients in the Nuffield Department of Surgery treated for craniopharyngiomas. Thirty-two cases were found, in 21 of which the tumour involved essentially the areas round the floor and sides of the third ventricle. In the remaining 11 the tumour was situated further forward and was difficult to distinguish in symptoms and appearance from a pituitary tumour.

The notes of these 32 cases were examined closely for evidence of memory disturbances, and the distribution of patients according to whether or not such evidence was present is shown for the two types of tumour in Table $I$. It will be seen that

TABLE I

DISTRIBUTION OF PATIENTS WITH CRANIOPHARYNGIOMAS ACCORDING TO LOCALIZATION OF TUMOUR AND DEGREE OF MEMORY DISTURBANCE

\begin{tabular}{|c|c|c|c|c|c|c|c|c|}
\hline \multirow{3}{*}{$\begin{array}{c}\text { Age } \\
\text { in } \\
\text { Years }\end{array}$} & \multicolumn{4}{|c|}{ Third Ventricle Syndrome } & \multicolumn{4}{|c|}{ Chiasmal Syndrome } \\
\hline & \multirow{2}{*}{$\begin{array}{l}\text { No. of } \\
\text { Patients }\end{array}$} & \multicolumn{3}{|c|}{$\begin{array}{c}\text { Memory } \\
\text { Disturbance }\end{array}$} & \multirow{2}{*}{$\begin{array}{l}\text { No. of } \\
\text { Patients }\end{array}$} & \multicolumn{3}{|c|}{$\begin{array}{c}\text { Memory } \\
\text { Disturbance }\end{array}$} \\
\hline & & Severe & $\begin{array}{l}\text { Mod- } \\
\text { erate }\end{array}$ & None & & Severe & $\begin{array}{l}\text { Mod- } \\
\text { erate }\end{array}$ & None \\
\hline $0-20$ & 7 & $\mathbf{0}$ & 3 & 4 & 6 & 0 & $\mathbf{0}$ & 6 \\
\hline $21-40$ & 6 & 2 & 3 & 1 & 2 & $\mathbf{0}$ & $\mathbf{0}$ & 2 \\
\hline $41-60$ & 8 & 6 & 1 & 1 & 3 & 0 & 0 & 3 \\
\hline Totals & 21 & 8 & 7 & 6 & 11 & 0 & 0 & 11 \\
\hline
\end{tabular}

whereas nearly three-quarters, or $0.72 \%$, of the patients with tumours involving the third ventricle showed some degree of memory impairment, there was not a single such case among the group in which the tumour was further forward. The frequency of mental symptoms was higher in the older groups, but some impairment was also seen in nearly half the children. Thus it appears that the memory defects cannot be specific to the type of lesion, but are associated with its localization.

In order to substantiate these conclusions the records of a number of other patients with discrete third ventricle tumours - other than craniopharyngiomas-were also examined, and the findings agreed closely with the above. However, there was also some degree of either raised intracranial pressure or hydrocephalus in each of these cases, so that it may well be suspected that the memory disturbances associated with tumours of the third ventricle were due to generalized cerebral derangement rather than to local pressure. 
In Cases 1-4, described here, the possibility of the mental symptoms being due to raised intracranial pressure was virtually ruled out, but it was decided further to compare the incidence of memory disturbances in the third ventricle tumours with that in posterior fossa tumours.

Among the patients admitted to the Nuffield Department of Surgery between June, 1950 and 1952 , there were 24 patients aged between 10 and 60 with verified tumours of the posterior fossa, and evidence that intracranial pressure had been raised at some period during their illness. The incidence of memory disturbances in this group of patients is shown in Table II. In comparison with the high

TABLE II

DISTRIBUTION OF PATIENTS WITH POSTERIOR FOSSA TUMOURS ACCORDING TO PRESENCE OR ABSENCE OF MEMORY DISORDER

\begin{tabular}{c|c|c|c}
\hline $\begin{array}{c}\text { Age in } \\
\text { Years }\end{array}$ & $\begin{array}{c}\text { No. of } \\
\text { Patients }\end{array}$ & \multicolumn{2}{|c}{ Memory Disorder } \\
\cline { 2 - 3 } & 2 & Present & Absent \\
\hline $10-20$ & 11 & 3 & 0 \\
$21-40$ & 11 & 6 & 8 \\
$41-60$ & 24 & 11 & 5 \\
\hline Totals & 24 & 13 \\
\hline
\end{tabular}

proportion of memory disturbances seen in third ventricle tumours (see Table I), under half $(0.45 \%)$ of the patients with tumours of the posterior fossa show comparable disturbances. The fact that some of them do so does not necessarily argue against the hypothesis that amnesia is associated with disturbance in and around the third ventricle, because posterior fossa tumours not infrequently cause physical disturbances commonly referred to the third ventricle. Thus, it is well known that posterior fossa tumours often lead to amenorrhoea, impotence, diabetes insipidus, and other physical manifestations of hypopituitarism and hypothalamic disturbance. These are the effects of dilatation of, and increased pressure in, the third ventricle, which are the common results of posterior fossa tumours.

As in the craniopharyngiomas, it was found on further analysis of the 24 cases with posterior fossa tumours that the incidence of mental disturbances was higher among the older patients than among the younger ones (see Table II). The implication of this will be discussed later on.

\section{The Site of Lesions Associated with Impaired Memory}

Of the 180 patients studied during this investigation, a large proportion of those showing mental impairment was found to exhibit specific disabilities such as dysphasia, dysarthria, spatial disorientation, apraxia, etc. There were only 26 patients in whom it was felt that memory impairment was the outstanding mental defect. In many of these cases the tumours were infiltrating and precise localization could not be given with certainty. However, the predominant site of lesion in each of these 26 cases was estimated, and the frequency for each site is shown in Table III. It will be seen that more cases have deep mid-line lesions than have lesions in all other areas of the brain together.

TABLE III

DISTRIBUTION OF PATIENTS WITH SPECIFIC DISTURBANCES OF MEMORY ACCORDING TO PREDOMINANT SITE OF LESION

\begin{tabular}{c|c|c|c|c|c|c}
\hline $\begin{array}{c}\text { Area of } \\
\text { Lesion }\end{array}$ & $\begin{array}{c}\text { Pos- } \\
\text { terior } \\
\text { Fossa }\end{array}$ & $\begin{array}{c}\text { Right } \\
\text { Hemi- } \\
\text { sphere }\end{array}$ & $\begin{array}{c}\text { Left } \\
\text { Hemi- } \\
\text { sphere }\end{array}$ & $\begin{array}{c}\text { Mid- } \\
\text { line, } \\
\text { Deep }\end{array}$ & $\begin{array}{c}\text { Mid- } \\
\text { line, } \\
\text { Cortical }\end{array}$ & Frontal \\
${$\cline { 1 - 2 }$} \begin{array}{c}\text { Number } \\
\text { patients } \\
\text { (out of } \\
\text { 26) }\end{array} }$ & 4 & 0 & 3 & 15 & 0 & 4 \\
\hline
\end{tabular}

It should also be mentioned, however, that the mental pictures were not identical in all these cases. In the four posterior fossa cases the patients showed considerable retardation and dementia as well as amnesia, and it was difficult to say how much of the memory defect was due to these factors. In the three left hemisphere lesions there was some speech disorder, which made mental testing unreliable, and in the frontal cases there was gross perseveration and fatuousness and the patients gave the impression that they were not bothering to remember rather than that they were unable to do so. In the 15 cases of deep mid-line lesion, on the other hand, the patients were often drowsy and apathetic if unstimulated, but once roused were alert, cooperative, and capable of considerable intellectual activity, although grossly amnesic and sometimes even showing the complete Korsakov syndrome.

\section{Discussion}

From whatever aspect the material reported here is analysed, it indicates that impairment of memory is most frequent, pronounced and specific when the area of the brain surrounding the floor and sides of the third ventricle is damaged. Speaking generally, lesions further forward, in the frontal area, often result in the patients not bothering to use their memories, while lesions of a cerebral hemisphere may cause loss of memory for particular skills, but the patients remain capable of remembering events ; lesions of the posterior fossa may make the patients 
retarded and depressed and unable to think of remembering. With lesions in and around the third ventricle, however, the patients frequently retain good personality and intellect but show gross defects of memory. The loss is not for particular events, nor for immediate appreciation of impressions, it is rather for their normal endurance and retention.

Apart from the site of the lesion, however, it is possible that other factors may be involved in determining the memory disturbance, so that the relationship between these factors and amnesia should be considered.

Increased Intracranial Pressure.-Evidence suggesting that memory disturbances are due to a generalized cerebral derangement has already been discussed, and the frequency of raised intracranial pressure in cases of tumour of the third ventricle raises the possibility that the amnesia noted in these cases may be the result of secondary disturbances of a more generalized nature. This hypothesis has already been considered and rejected by Busch (1940), and the observations reported here support his conclusion. In the four cases described in detail-and Case 4 in particular-intracranial pressure was reduced to normal without affecting memorizing. Conversely, in the cases of posterior fossa tumour, in which intracranial pressure was invariably raised, the incidence of memory disturbances was smaller and usually of a different nature from that in those of third ventricle tumour.

Relationship with Other Psychological Defects.The presence of at least some disturbances in association with severe memory defects-such as apathy, dementia, disorientation, confabulationraises the possibility that the memory defects may themselves be secondary to disturbances in some of these other mental spheres. However, comparison between the mental state seen in the patients with third ventricle lesions and that in patients with lesions in other areas of the brain, indicates that this is unlikely to be the case. The patients with posterior fossa tumours showed considerably greater apathy and dementia in relation to amnesia than did those with lesions around the third ventricle; and patients with frontal lobe lesions showed considerably more in the way of personality changes. Thus, the disturbances of memory, though they may coincide with other mental disorders, cannot be considered as primarily due to them.

Relationship to Age at Time of Onset.-In agreement with Walther-Büel (1951) and Bleuler
(1951), it was noted here that memory disorders are more common in older people than in younger ones. However, from this finding it does not necessarily follow that the amnesic reaction is independent of the cerebral area involved and due only to the patient's age at the time of illness. A similar association is found to occur between the degree of mental impairment and age at the time of lesion in other functional areas of the brainnotably the temporal lobe-without this association being taken to imply that the locality of a lesion in adults is unconnected with its mental sequels.

Lowered Level of Consciousness and Somnolence.As shown by the E.E.G. recordings of the individual cases reported here, impairment of memory was closely related to generalized lowering of cortical activity.

These conclusions suggest that memory is as much, if not more, a function of generalized wakefulness and consciousness as it is of intellect, personality, or mood. The exact mechanism by which the functions are connected and conducted, however, is still unexplained. Although the evidence presented above has little to offer in this respect, it does suggest that further study of the functions of the area round the third ventricle is well worth while, as it might yield especially valuable information about the connexion between mental and cerebral activity.

\section{Summary}

One hundred and eighty patients with verified intracranial lesions have been interviewed by psychologists in a neurosurgical unit in order to ascertain whether there is any area of the brain the destruction of which is specifically associated with impairment of memory.

The data obtained have been analysed from three aspects : (a) Four cases in which impairment of memory and site of lesion were clearly defined and well localized are described in detail ; (b) the incidence of memory disturbances in tumours of the third ventricle has been compared with that in other well localized intracerebral tumours; (c) patients with obvious and clear-cut defects of memory have been examined for the most common site of lesion.

All analyses support the conclusion that memory impairment is most common and specific when the area surrounding the floor and walls of the third ventricle is disturbed.

The relationship between memory disturbances and other possible causal mechanisms is briefly discussed. 
We would like to acknowledge our indebtedness to the late Sir Hugh Cairns for the initiation and thesis of the above work and for valuable guidance during the earlier part of the investigations ; also to Miss M. Davidson for the psychological assessment of one patient and Miss $\mathbf{M}$. Taylor for E.E.G. records and interpretations.

\section{REFERENCES}

Benedek, L., and Juba, A. (1941). Arch. Psychiat. Nervenkr. 114, 366. Bleuler, M. (1951). Brit. med. J., 2, 1233.

Busch, E. (1940). Acta psychiat. Kbh., 15, 257.

Busch, E. (1940). Acta psychiat.
Cairns, H. (1952). Brain, 75, 109.

-, and Mosberg, W. H. (1951). Surg. Gynec. Obstet., 92, 545.
Campbell, A. C. P., and Russell, W. R. (1941). Quart. J. Med., 34 (n.s.10), 41

Carmichael, E. A., and Stern, R. O. (1931). Brain, 54, 189.

Conrad, K., and Üle, G. (1951). Disch. Z. Nervenheilk., 165, 430.

Foerster, O., and Gagel, O. (1934). Z. ges. Neurol. Psychiat., 149, 312.

Gamper, E (1928). Dtsch. Z. Nervenheilk, 102, 122

Hermann, K. (1950). Proc. 12th int. Congr. Psychol., Edinburgh, 1948, p. 71. Oliver and Boyd, Edinburgh.

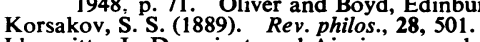

Lhermitte, J., Doussinet, and Ajuriaguerra, de (1937). Rev. Neurol., Paris, 68, 709.

McFie, J., and Piercy, M. F. (1952). Brain, 75, 292

Poppen, J. L., Reyes, V., and Horrax, G. (1953). J. Neurosurg., 9 242.

Sprofkin, B. E., and Sciarra, D. (1952). Neurology, 2, 427.

Walther-Büel, H. (1951). "Die Psychiatrie der Hirngeschwülste . . ." Acta neurochir., Suppl. 2.

\section{THE FEBRUARY (1954) ISSUE}

The February (1954) issue contains the following papers :-

Traumatic Epilepsy after Closed Head Injury. Gilbert Phillips.

Demonstration of ${ }^{82} \mathrm{BR}$ in Nerve Cells. Sven-Olof Brattgard and Torsten Lindqvist.

Frontal Lobe Wounds Causing Disinhibition. A Study of Six Cases. Hugh F. Jarvie.

A Histological and Chemical Study of Three Cases of Diffuse Cerebral Sclerosis. W. Blackwood and J. N. Cumings. Post-encephalitic Parkinsonism with Amyotrophy. J. G. Greenfield and W. B. Matthews.

A Study of Eight Surgically Treated Cases of Spontaneous Sub-cortical Haematoma. Aloys Werner.

Dimercaprol in the Pre-neurological Stage of Wilson's Disease (Hepatolenticular Degeneration). C. G. Warnock and D. W. Neill.

Studies of the Connexions of the Fornix System. H. M. Daitz and T. P. S. Powell.

The Treatment of Dystrophia Myotonica with A.C.T.H. Oliver Garai.

A number of copies are still available and may be obtained from the Publishing Manager, British Medical Association, Tavistock Square, W.C.1, price 12s. 6d. 